Personalidade Acadêmica Homenageada:

Carlos Aurélio Mota de Souza (Universidade Ibirapuera - UNIB)

\title{
A INSTITUIÇÃO DO CONTROLE PRÉVIO E A ALTERAÇÃO DOS CRITÉRIOS PARA SUBMISSÃO DE ATOS DE CONCENTRAÇÃO PERANTE O CONSELHO ADMINISTRATIVO DE DEFESA ECONÔMICA: COMPARAÇÃO ENTRE OS CENÁRIOS ANTERIOR E POSTERIOR À LEI N.․ 12.529/2011
}

THE INSTITUTION OF AN "A PRIORI” MERGER CONTROL MODEL AND THE MODIFICATION OF THE CRITERIA FOR SUBMISSION OF CONCENTRATION ACTS BEFORE THE BRAZILIAN ADMINISTRATIVE COUNCIL OF ECONOMIC DEFENSE: COMPARISON BETWEEN THE SCENARIOS BEFORE AND AFTER THE BRAZILIAN LAW 12.529 OF 2011

EVERTON DAS NEVES GONÇALVES Professor Titular credenciado no Programa de Pós-Graduação em Direito da Universidade Federal de Santa Catarina (PPGD/UFSC); Pesquisa Análise Econômica do Direito e Direito Econômico; Coordenador do Centro de Estudos JurídicoEconômicos e de Gestão para o Desenvolvimento (CEJEGD) do Centro de Ciências Jurídicas (CCJ/UFSC). Doutor em Direito Econômico pela Universidade Federal de Minas Gerais (UFMG/MG); Doctor en Derecho Internacional Económico en la Universidad de Buenos Aires (UBA/ Bs. As.) Argentina; Mestre em Direito, na área de Instituições Jurídico-Políticas, pela Universidade Federal de Santa Catarina (UFSC/SC); Especialista em Comércio Exterior e Integração Econômica no MERCOSUL pela FURG/RS; Graduado em Direito pela Unianchieta de Jundiaí/SP e em Ciências Econômicas pela Universidade Federal do Rio Grande (FURG/RS); Especialista em Administração Universitária pela FURG/RS. Universidade Federal de Santa Catarina- evertong@vetorial.net http://orcid.org/0000-0001-8644-4603 


\section{Personalidade Acadêmica Homenageada:}

Carlos Aurélio Mota de Souza (Universidade Ibirapuera - UNIB)

\section{RESUMO}

O presente artigo visa descrever as principais alterações trazidas pela Lei $\mathrm{n}$. 12.529/2011 ao controle estrutural da concorrência no Brasil, quais sejam, a modificação dos requisitos para submissão e a implantação do modelo de controle prévio dos atos de concentração. Para tanto, são apresentados: (i) noções acerca da atuação preventiva (estrutural) do CADE, (ii) distinções entre os modelos de controle sob a égide das Leis n.. 8.884/1994 e n.ำ 12.529/2011, (iii) critérios para submissão das concentrações sob a perspectiva de ambas as legislações, e (iv) dados quantitativos anteriores e posteriores à reforma. Trata-se de pesquisa qualitativa exploratória, de procedimento monográfico, de abordagem indutiva e técnica de pesquisa bibliográfica. A partir dos autores e dados apresentados, conclui-se que a atuação do Cade, a partir da entrada em vigor da nova legislação antitruste, foi substancialmente modificada, de modo a se tornar mais dinâmica e eficiente.

PALAVRAS-CHAVE: Controle Estrutural; Atos de Concentração; Lei N.. 12.529/2011; Lei N. 8.884/1994; Conselho Administrativo de Defesa Econômica.

\section{ABSTRACT}

This paper aims to describe the main changes introduced by the Brazilian law 12.529 of 2011 in the merger control, namely, the modification of the submission requirements and the implementation of an "a priori" merger control model. The following topics are 


\section{Personalidade Acadêmica Homenageada:}

Carlos Aurélio Mota de Souza (Universidade Ibirapuera - UNIB)

studied: (i) notions about the preventive action of Brazilian Administrative Council of Economic Defense; (ii) distinctions between the merger control models under the Brazilian laws 8.884 of 1994 and 12.529 of 2011; (iii) criteria for submitting concentrations under the perspective of both legislations, and (iv) pre and post-reform quantitative data. This is a qualitative exploratory research, with a monographic procedure method, an inductive investigate methodology and a bibliographic research technique. From the authors and data presented, it is concluded that the activities of Brazilian Administrative Council of Economic Defense, since the entry into force of the new antitrust legislation, have been substantially modified in order to become more dynamic and efficient.

KEYWORDS: Merger Control; Concentration Act; Brazilian Law 12.529 of 2011; Brazilian Law 8.884 of 1994; Brazilian Administrative Council of Economic Defense.

\section{INTRODUÇÃO}

O artigo descreve as principais alterações trazidas pela Lei n. ${ }^{0}$ 12.529/2011 ao controle estrutural da concorrência no Brasil ${ }^{1}$. Partindo da noção de que a Nova Lei Antitruste trouxe inovações de suma importância para o fortalecimento da política antitruste no País, busca-se apresentar as inovações implementadas (alteração dos requisitos para submissão e implantação do modelo de controle prévio), bem como analisar os reflexos decorrentes destas na prática diária do Conselho Administrativo de Defesa Econômica (Cade).

Nesse sentido, tem-se como objetivo geral descrever as alterações decorrentes da nova legislação, assim como os cenários anterior e posterior à reforma. Por sua vez, são objetivos específicos: (i) delinear a atuação preventiva do Cade, (ii) descrever o cenário pré-reforma e as alterações trazidas pela Lei $\mathrm{n} .{ }^{\circ}$

\footnotetext{
${ }_{1}^{1}$ Para maiores esclarecimentos, ver GONÇALVES e STELZER (2012-A. 263-283).
} 


\section{Personalidade Acadêmica Homenageada:}

\section{Carlos Aurélio Mota de Souza (Universidade Ibirapuera - UNIB)}

12.529/2011, e (iii) apresentar dados quantitativos acerca da tramitação dos atos de concentração perante o Cade.

A metodologia aplicada à pesquisa é indutiva, na medida em que partir de dados da realidade, captados via pesquisa indireta, busca-se compreender as alterações decorrentes da inovação legislativa. Quanto à técnica de pesquisa, esta é eminentemente bibliográfica.

O Antitruste, no Brasil, por excelência, é institucionalizado pelo trabalho preventivo e repressivo do Cade que tem jurisdição sobre todo o território nacional atuando, inclusive e para além de coibir praticas infrativas, no disciplinamento dos atos de concentração.

\section{A ATUAÇÃo PREVENTIVA dO CONSELHO ADMINISTRATIVO DE DEFESA ECONÔMICA}

A Lei n. - 12.529/2011 (2018) reestruturou o Sistema Brasileiro de Defesa da Concorrência (SBDC), que passou a ser composto pelo Conselho Administrativo de Defesa Econômica (Cade) - autarquia federal, vinculada ao Ministério da Justiça - e pela Secretaria de Acompanhamento Econômico do Ministério da Fazenda (Seae).

A partir da referida reestruturação, as competências dos órgãos atuantes no SBDC foram revistas. Nesse cenário, à Seae restou a advocacia da concorrência, ou seja, o poder-dever de promoção da concorrência perante os órgãos governamentais e a sociedade. Já ao Cade, que atua por meio do Tribunal Administrativo de Defesa Econômica (Tade), da Superintendência-Geral (SG) e do Departamento de Estudos Econômicos (DEE), compete a atividade judicante, exercida por meio dos controles estrutural e de condutas.

Todavia, com a entrada em vigor do Decreto n. 9 9.266/2018 (2018), a Seae foi extinta, sendo suas atribuições distribuídas entre a Secretaria de Promoção da Produtividade e Advocacia da Concorrência (Seprac) - voltada à advocacia da concorrência - e a Secretaria de Acompanhamento Fiscal, Energia e Loteria (Sefel) - 


\section{Personalidade Acadêmica Homenageada:}

Carlos Aurélio Mota de Souza (Universidade Ibirapuera - UNIB)

voltada à formulação e execução da política fiscal, de políticas públicas no setor de energia e de regulação de loterias (MINISTÉRIO DA FAZENDA, 2018).

É da atuação dúplice do Cade, preventiva (controle estrutural) e repressora (controle de condutas), que decorre a eficácia plena da proteção concorrencial (GABAN; DOMINGUES, 2012). Segundo Fábio Ulhoa Coelho (2011, p. 43), o órgão antitruste atua preventivamente quando "[...] aprova operações societárias, como incorporação ou fusão, e demais atos de que possa decorrer prejuízo à concorrência ou dominação de mercado", bem como atua repressivamente quando "[...] julga os processos administrativos pertinentes à infração da ordem econômica, impondo sanções às pessoas que incorrerem em conduta ilícita" (COELHO, 2011, p. 43).

Especialmente no que tange ao controle preventivo (ou estrutural) da concorrência, objeto do presente estudo, a Lei n.. 12.529/2011 (2018) instituiu três procedimentos administrativos específicos passíveis de instauração perante o CADE: (i) processo administrativo para análise de ato de concentração econômica, (ii) procedimento administrativo para apuração de ato de concentração econômica, e (iii) processo administrativo para imposição de sanções processuais incidentais.

O primeiro procedimento é a maior e melhor expressão da atuação preventiva do CADE na Legislação brasileira. Trata-se da instauração de procedimento com vistas à aprovação (integral ou com ressalvas) ou reprovação de um ato de concentração, devidamente notificado perante o órgão judicante do SBDC, quando preenchidos os requisitos de submissão. O segundo procedimento, por sua vez, tem como escopo a apuração acerca da necessidade de submissão de determinado ato de concentração não notificado. Por fim, o terceiro procedimento "[...] relaciona-se ao descumprimento de deveres ancilares das empresas representadas ou que pleiteiam a aprovação de operação de concentração econômica" (FORGIONI, 2015, p. 148). O foco do presente trabalho está no primeiro procedimento, o qual sofreu grandes transformações com a transição do regime disposto na Lei n. ${ }^{\circ}$ 8.884/1994 para o novo regime da Lei $n$. - 12.529/2011 - com destaque aos critérios para submissão e ao momento da notificação.

É importante salientar, ainda, que os atos de concentração - enquanto associação entre empresas ensejadora de alterações estruturais e de gestão das 


\section{Personalidade Acadêmica Homenageada:}

Carlos Aurélio Mota de Souza (Universidade Ibirapuera - UNIB)

mesmas - não são prejudiciais per se. Se por um lado, os atos de concentração podem ensejar danos à concorrência ( $v$.g. abuso de poder econômico, caracterizado conforme $\S 4^{\circ}$ do art. 173 da Constituição da República Federativa do Brasil (CRFB/88, 2018) implicando aumento arbitrário de preços, eliminação da concorrência, dominação de mercados e, ainda, exploração dos consumidores), por outro, exercem papel positivo ao permitir a recuperação de empresas atingidas por crises financeiras e a otimização das condições de distribuição (FÁZZIO JÚNIOR, 2014).

Na medida em que compete às políticas antitruste evitar que a livre ação das forças de mercado seja afetada pelas estratégias empresariais, levando-se em consideração que os atos de concentração têm como motivação a perspectiva econômica, o controle estrutural é indispensável, a fim de permitir a fiscalização do incremento do poder de mercado que deles advém (FAGUNDES, 2012).

Dada a importância do controle estrutural para a defesa da concorrência, nos próximos tópicos serão exploradas as duas principais alterações trazidas pela Lei $\mathrm{n}$. 12.529/2011, quais sejam: (i) o controle prévio de concentração, e (ii) a indicação de critérios mais claros de submissão. Por fim, serão apresentados dados empíricos sobre o controle estrutural anterior e posteriormente à reforma.

\section{MODELOS DE CONTROLE DOS ATOS DE CONCENTRAÇÃO}

O controle estrutural da concorrência, consistente na apreciação de atos de concentração cuja submissão perante o Órgão antitruste é obrigatória, pode se dar de forma prévia ou posterior.

No modelo prévio, exige-se a submissão do ato de concentração a ser implementado ao crivo da Entidade Antitruste, com vistas a evitar alterações negativas do mercado. Nessa perspectiva, "[...] as empresas não podem se concentrar antes que o CADE as autorize a proceder à concentração. Assim sendo, o controle dos atos de concentração que são analisados pelo CADE é sempre feito antes da concentração se efetivar" (CASTRO, 2012, p. 68). 


\section{Personalidade Acadêmica Homenageada:}

\section{Carlos Aurélio Mota de Souza (Universidade Ibirapuera - UNIB)}

O sistema prévio de controle estrutural é adotado pelas maiores agencias antitruste nos diversos países, tais como; nos Estados Unidos da América (EUA), na União Europeia (UE) e na maioria dos países membros da Organização para Cooperação e Desenvolvimento Econômico (OCDE). Nos EUA, a premerger notification foi instituída em 1976, pelo Hart-Scott-Rodino Act, que prevê período de espera a fim de viabilizar que as autoridades competentes coletem e apreciem as informações relacionadas à operação de concentração a ser realizada (FORGIONI, 2015). Na UE, o regulamento CE 139/2004 prevê a necessidade de notificação das concentrações de dimensão comunitária perante a Comissão, antes de sua realização (CASTRO, 2013).

No que concerne ao controle posterior "[...] as empresas submetem à análise da autoridade concorrencial o negócio jurídico após a sua realização, comprometendo, em muitos casos, a plena efetividade da decisão do órgão de defesa da concorrência" (CORDOVIL et al, 2011, p. 208). Em suma, ao contrário do que ocorre no controle prévio, em que a notificação deve ser anterior à consumação do ato de concentração, no sistema de controle a posteriori, as empresas realizam o ato de concentração, devendo notificar a autoridade antitruste no prazo determinado em lei.

O Brasil, sob a égide da Lei $n .$. 8.884/1994 (2018), adotava sistema misto, admitindo tanto a submissão prévia, quanto a posterior. Nesse sentido, o art. 54, §4으, da referida Lei, previa que "Os atos de que trata o caput deverão ser apresentados para exame, previamente ou no prazo máximo de quinze dias úteis de sua realização, mediante encaminhamento da respectiva documentação em três vias à SDE, que imediatamente enviará uma via ao CADE e outra à SEAE".

A adoção do modelo de controle a posteriori era alvo de críticas, na medida em que a posterior rejeição do ato de concentração poderia ensejar a rescisão dos contratos já realizados. Para os críticos, o modelo geraria insegurança jurídica, pois mesmo após a consumação do ato de concentração, as partes estariam sujeitas à avaliação do Órgão Antitruste Pátrio pelo prazo de 120 dias (SCHNEIDER, 2012, p. 71). Para além da insegurança, havia também a possibilidade do ato de concentração 


\title{
Personalidade Acadêmica Homenageada:
}

Carlos Aurélio Mota de Souza (Universidade Ibirapuera - UNIB)

gerar consequências anticoncorrenciais irreversíveis, bem como altos custos inerentes ao desfazimento do negócio reprovado.

Com a reforma do SBDC, o Brasil passou a adotar o modelo prévio do controle estrutural. Nesse sentido, o art. 88, § 2º da Lei n.․ 12.529/2011 (2018), dispõe que "O controle dos atos de concentração de que trata o caput deste artigo será prévio e realizado em, no máximo, 240 (duzentos e quarenta) dias, a contar do protocolo de petição ou de sua emenda". Ensina Forgioni (2015, p. 425):

\begin{abstract}
A Lei é bastante clara ao afirmar, no $\S 2^{\circ}$ do art. 88 , que o controle dos atos de concentração pelo CADE será prévio e que estes não poderão ser consumados antes de apreciados, sob pena de nulidade e multa pecuniária. A concentração não autorizada e efetivada, na medida em que implicar domínio de mercado, abuso de posição dominante ou prejuízo concorrencial é capaz de configurar infração à ordem econômica, determinando a incidência do art. 36, caput, exigindo a abertura de processo para a sua investigação. Sem a autorização, o ato não pode licitamente produzir sua eficácia plena.
\end{abstract}

A referida modificação no sistema de controle dos atos de concentração foi alvo de críticas e elogios. Quem defende o controle prévio, advoga no sentido de que não admitir o controle posterior evita a ocorrência de impactos econômicos irreversíveis no mercado (CASTRO, 2012, p. 69). Por outro lado, há quem defenda que o controle prévio restringe a liberdade de iniciativa, presumindo a ilegalidade do ato (ANDRADE; PASSOS; MATTOS, 2017, p. 19 apud CASTRO, 2013, p. 23). Outrossim, haveria ainda o problema relacionado ao tempo de espera pela decisão a ser despendido pelos agentes econômicos.

Seja melhor ou pior, fato é que o modelo vigente atualmente é aquele do controle a priori dos atos de concentração, de tal modo que, preenchidos os requisitos legais, a concentração deverá ser submetida ao crivo do Cade, sob pena de configuração da consumação prévia do ato de concentração (gun jumping), prática vedada pelo art. 88, § 3ำ da Lei Antitruste. 
Personalidade Acadêmica Homenageada:

Carlos Aurélio Mota de Souza (Universidade Ibirapuera - UNIB)

\section{CRITÉRIOS PARA NOTIFICAÇÃO DOS ATOS DE CONCENTRAÇÃO}

No SBDC, quer seja sob a vigência da Lei $n . .98 .884 / 1994$, quer seja da Lei $n .$. 12.529/2011, sempre existiu um rol de requisitos a ser preenchido, a fim de ensejar a necessidade de apreciação da concentração perante o Cade. Em suma, não são todos os atos de concentração que interessam ao Órgão Antitruste, mas somente aqueles legalmente instituídos. Ocorre que, com a alteração legislativa, os critérios de submissão foram totalmente reformulados.

Nos termos do art. 54, caput, da Lei n.. 8.884/2011 (2018), "Os atos, sob qualquer forma manifestados, que possam limitar ou de qualquer forma prejudicar a livre concorrência, ou resultar na dominação de mercados relevantes de bens ou serviços, deverão ser submetidos à apreciação do CADE". De forma mais especifica, o $\S 3^{\circ}$ do referido artigo previa a necessidade de submissão perante Cade de operações de concentração que: (i) impliquem participação de empresa ou grupo de empresas resultante em vinte por cento de um mercado relevante, ou (ii) qualquer dos participantes tenha registrado faturamento bruto anual no último balanço equivalente a $R \$ 400.000 .000,00$ (quatrocentos milhões de reais). Restava, pois, real dúvida quanto ao fato de dever ser apresentado ou não o ato de concentração ao SBDC já que, somente a posteriori, o SBDC, através da Seae definiria, efetivamente a fatia de participação dos agentes concentrados no mercado relevante. Sobre a questão, disserta Bagnoli (2008, p. 163-164):

Verifica-se da leitura do caput do art. 54 a abrangência dos casos em que se deve submeter uma operação à análise do CADE, pois é ele o órgão competente para aprova-la ou não. Fica, certamente, a dúvida em saber quando se deve apresentar uma operação, já que o prejuízo à concorrência ou a dominação de mercado são conceitos subjetivos, que na defesa das partes envolvidas jamais ocorrerão. Primeiramente, cumpre ressaltar 0 entendimento de que é o CADE que dirá se o ato pode limitar ou prejudicar a livre concorrência ou resultar na dominação de mercados relevantes de bens ou serviços, devendo as partes requerentes, portanto, apresenta-lo. [...] A Lei, entretanto, aponta dois critérios objetivos que auxiliam os entes envolvidos numa operação, a saber, se deverão, de fato, apresentar o caso ao CADE, conforme consta no $\S 3$ do art. 54. [...] Adotando-se estes critérios, significa que em qualquer operação em que as partes envolvidas detenham, mesmo que isoladamente (antes do ato), $20 \%$ de participação em um mercado relevante, ou uma das partes tenha registrado, por si ou conjuntamente com 


\section{Personalidade Acadêmica Homenageada: \\ Carlos Aurélio Mota de Souza (Universidade Ibirapuera - UNIB)}

o grupo econômico a que esteja ligada, $R \$ 400$ milhões, essa operação deve ser submetida à apreciação do CADE, que dirá se ela limita ou prejudica a livre concorrência ou resulta na dominação de mercados relevantes de bens ou serviços. Ou seja, os requisitos para se submeter uma operação à análise do CADE estão na verdade no $\S 3^{\circ}$ do art. 54 e não no caput.

Uma interpretação literal do caput do art. 54, dissociada de seu § 3ำ, poderia gerar grandes dúvidas quanto aos atos passíveis de submissão perante o Cade. De outro lado, havia ainda a exigência de definição da participação no mercado relevante, o que apresentava grande complexidade.

Com a entrada em vigor da Lei $\mathrm{n} . \stackrel{0}{12.529 / 2011}$, os critérios foram totalmente alterados, apresentando-se requisitos mais objetivos, relacionados diretamente ao faturamento anual bruto dos agentes econômicos envolvidos. Ensinam Rodrigues e Araújo (2017, p. 37):

\footnotetext{
Nesse sentido, a Lei exclui o critério de participação de mercado e apresenta limites mais objetivos para a obrigatoriedade de notificação, além de exigir que os limiares sejam atingidos por ambas as partes envolvidas na operação. Segundo o artigo 88 da Lei $n^{\circ} 12.529 / 2011$, com valores atualizados pela Portaria Interministerial no 994, de 30 de maio de 2012, devem ser notificados ao CADE os atos de concentração, em qualquer setor da economia, em que pelo menos um dos grupos envolvidos na operação tenha registrado faturamento bruto anual ou volume de negócios total no Brasil, no ano anterior à operação, equivalente ou superior a $R \$ 750$ milhões, e pelo menos um outro grupo envolvido na operação tenha registrado faturamento bruto anual ou volume de negócios total no Brasil, no ano anterior à operação, equivalente ou superior a $\mathrm{R} \$ 75$ milhões.
}

De acordo com Forgioni (2015, p. 424), para se determinar se dada operação de concentração deve ser submetida à apreciação perante o CADE, é necessário verificar, cumulativamente, se: “[...] (i) trata-se de operação expressamente mencionada no art. 90, da Nova Lei Antitruste, e (ii) o faturamento dos agentes econômicos envolvidos alcança os patamares do art. 88, atualizados pela Postaria Interministerial n. 994/2012".

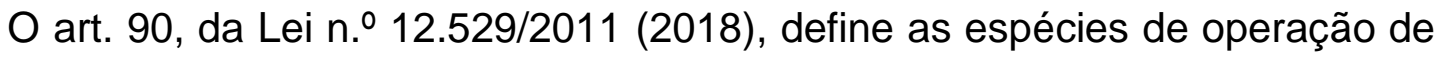
concentração submetidas ao crivo do Cade. In verbis: 


\title{
Personalidade Acadêmica Homenageada: \\ Carlos Aurélio Mota de Souza (Universidade Ibirapuera - UNIB)
}

\begin{abstract}
Art. 90. Para os efeitos do art. 88 desta Lei, realiza-se um ato de concentração quando: I - 2 (duas) ou mais empresas anteriormente independentes se fundem; II - 1 (uma) ou mais empresas adquirem, direta ou indiretamente, por compra ou permuta de ações, quotas, títulos ou valores mobiliários conversíveis em ações, ou ativos, tangíveis ou intangíveis, por via contratual ou por qualquer outro meio ou forma, o controle ou partes de uma ou outras empresas; III - 1 (uma) ou mais empresas incorporam outra ou outras empresas; ou IV - 2 (duas) ou mais empresas celebram contrato associativo, consórcio ou joint venture. Parágrafo único. Não serão considerados atos de concentração, para os efeitos do disposto no art. 88 desta Lei, os descritos no inciso IV do caput, quando destinados às licitações promovidas pela administração pública direta e indireta e aos contratos delas decorrentes.
\end{abstract}

Por outro lado, o art. 88, da mesma Lei, prevê os parâmetros de faturamento a serem levados em consideração. Nesse sentido, o teor do art. 1ํ, da Portaria Interministerial 994/2012 (2018), que atualizou os referidos valores:

Art. 1 Para os efeitos da submissão obrigatória de atos de concentração a analise do Conselho Administrativo de Defesa Econômica - CADE, conforme previsto no art. 88 da Lei 12.529 de 30 de novembro de 2011, os valores mínimos de faturamento bruto anual ou volume de negócios no país passam a ser de: I - $\mathrm{R} \$ 750.000 .000,00$ (setecentos e cinquenta milhões de reais) para a hipótese prevista no inciso I do art. 88, da Lei 12.529, de 2011; e II $\mathrm{R} \$ 75.000 .000,00$ (setenta e cinco milhões de reais) para a hipótese prevista no inciso II do art. 88, da Lei 12.529 de 2011.

É interessante salientar que a clareza e a taxatividade inerentes ao novo texto permitem que o controle de estruturas se dê de forma mais eficiente, na medida em que o administrado pode identificar de modo inequívoco a necessidade de submissão do negócio jurídico perante a autoridade estatal. A contrario sensu, a redação do artigo reduz a margem de interpretação do Cade, principalmente no que tange à desnecessidade de submissão de determinados atos que se enquadram nas exigências dos arts. 88 e 90, da Lei $n . .912 .529 / 11$, sem, contudo, apresentarem qualquer relevância concorrencial (CORDOVIL et al, 2011).

Por fim, tem-se ainda, no $\S 7^{\circ}$, do art. 88, da Lei n.. $12.529 / 2011$ (2018), a possibilidade da Autoridade Antitruste brasileira requisitar a submissão de atos de concentração que não preencham os índices de jurisdição. Nos termos da lei (2018), "É facultado ao CADE, no prazo de 1 (um) ano a contar da respectiva data de 


\section{Personalidade Acadêmica Homenageada:}

\section{Carlos Aurélio Mota de Souza (Universidade Ibirapuera - UNIB)}

consumação, requerer a submissão dos atos de concentração que não se enquadrem no disposto neste artigo".

Identificada a atuação preventiva do Cade quanto às estruturas de mercado, mediante específicos modelos de controle dos atos de concentração, segundo critérios técnicos e objetivos para notificação dos atos de concentração; necessário se faz verificar a efetividade do referido controle estrutural de mercado no Brasil. É o que se passa a ver.

\section{CONTROLE ESTRUTURAL EM NÚMEROS}

A Lei n.- 12.529/2011 trouxe alterações significantes em relação ao controle estrutural exercido pelo Cade. A alteração dos requisitos de submissão, assim como a estipulação da necessidade de prévia autorização para a consumação de concentrações, são mudanças significativas, capazes de alterar o cenário concorrencial nacional. A fim de verificar até que ponto essas inovações alteraram o cenário brasileiro, no presente tópico serão comparados dados anteriores e posteriores à reforma.

Um primeiro item a ser analisado diz respeito à entrada e saída de atos de concentração perante o Cade. Como se verifica nos Gráficos (1 e 2) abaixo, o número de atos de concentração submetidos à apreciação da Autoridade Antitruste Brasileira, após a reforma, vem diminuindo. Se entre 2008 e 2011 (período final de vigência de Lei n. $.8 .884 / 1994$ ) foram submetidos 2.466 atos de concentração perante o Cade, no primeiro quadriênio de vigência da Lei n.․ 12.529/2011 (até maio de 2016) foram 1.077 atos de concentração, ou seja, menos da metade. Houve sensível diminuição no número de casos analisados pelo Sistema, até porque, o nível de exigência para tornar um ato de concentração suscetível à análise pelo SBDC passou a ser mais flexível, na medida em que passou a perquirir das concentrações de maior grandeza envolvendo empresas com faturamento bruto; no ano anterior ao da fusão/incorporação/aquisição, maior de $R \$ 750.000 .000,00$ e de $R \$ 75.000,000,00$. Evidente, então, que, ao SBDC não importam concentrações que envolvam empresas 


\section{Personalidade Acadêmica Homenageada:}

\section{Carlos Aurélio Mota de Souza (Universidade Ibirapuera - UNIB)}

menores em termos de faturamento. Acredita-se isso deva ocorrer em virtude de evidente flexibilização normativa para a atuação competitiva dos agentes econômicos já que o SBDC não condena, nem mesmo, o monopólio per se.

Gráfico 1: Atos de Concentração: entrada e saída

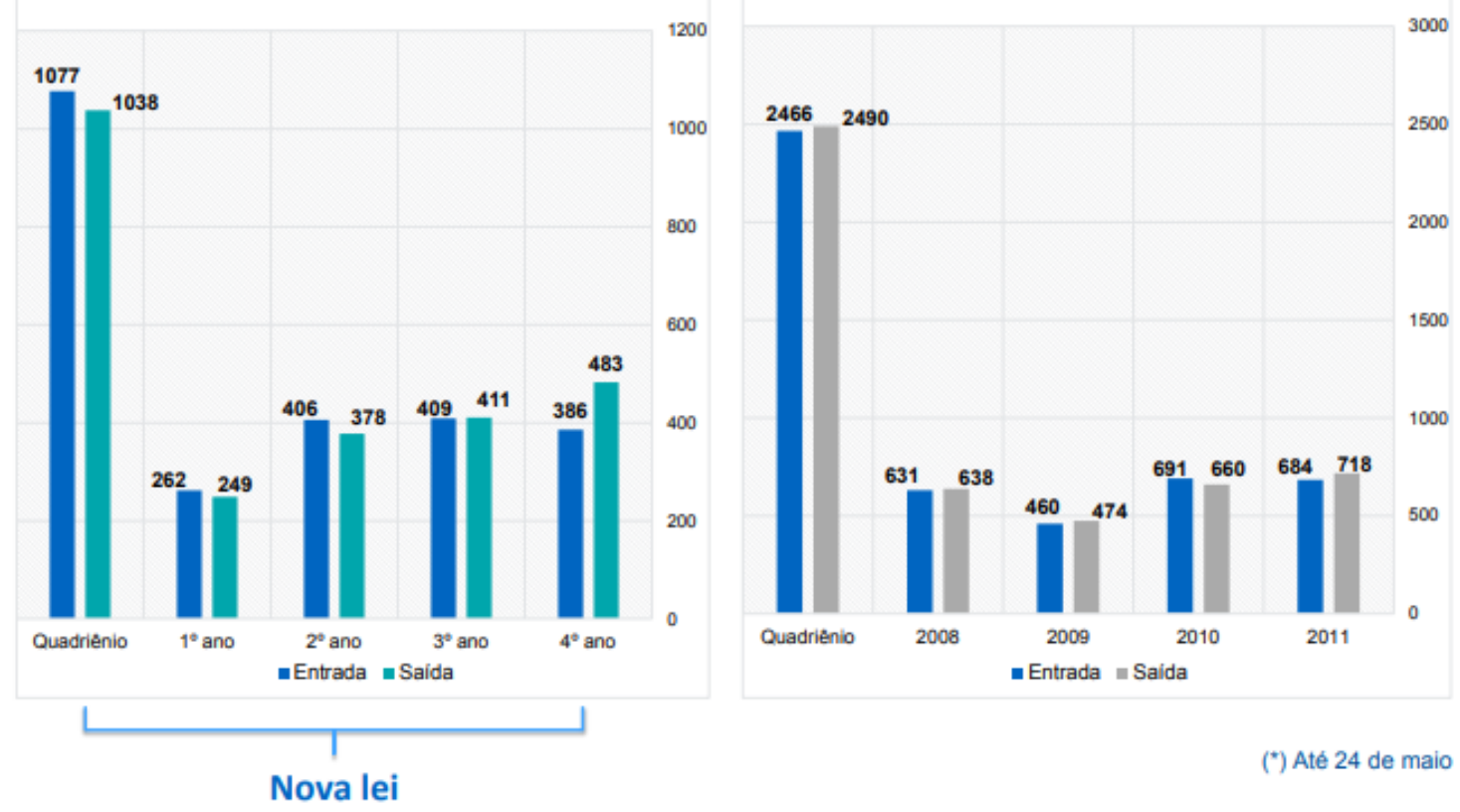

Fonte: Relatório CADE: Balanço 4 anos da nova lei $(2018$, p. 4)

A análise ano a ano, disposta no Gráfico 2 (abaixo) torna a alteração de cenário flagrante. No ano de 2012, no qual há atos notificados sob ambos os regimes legais, pois a Lei entrou em vigor no mês de maio daquele ano, foram notificados 626 atos de concentração, dos quais apenas 138 foram notificados sob o regime da Lei n.. $12.529 / 2011$. Salienta-se que a Lei nova vigorou por mais meses do que a Lei $n .$. 8.884/1994 no ano em questão.

Em que pese a clareza estatística, há de se ter a devida cautela para a apreciação fenomenológica; portanto, coeteris paribus, ainda que não seja possível afirmar com exclusividade a motivação da diminuição do número de atos de concentração apreciados pelo Cade, pode-se inferir, a partir dos dados apresentados, que a referida diminuição no número de atos apresentados: (i) decorreu da maior clareza quantos aos critérios de submissão dos atos de concentração no SBDC; e, 


\section{Personalidade Acadêmica Homenageada:}

\section{Carlos Aurélio Mota de Souza (Universidade Ibirapuera - UNIB)}

ou, ainda, (ii) teve como causa a majoração dos valores de faturamento anual bruto a percebidos pelas empresas envolvidas a fim de justificar a necessidade de apreciação pelo Cade.

Gráfico 2: Atos de concentração notificados por ano

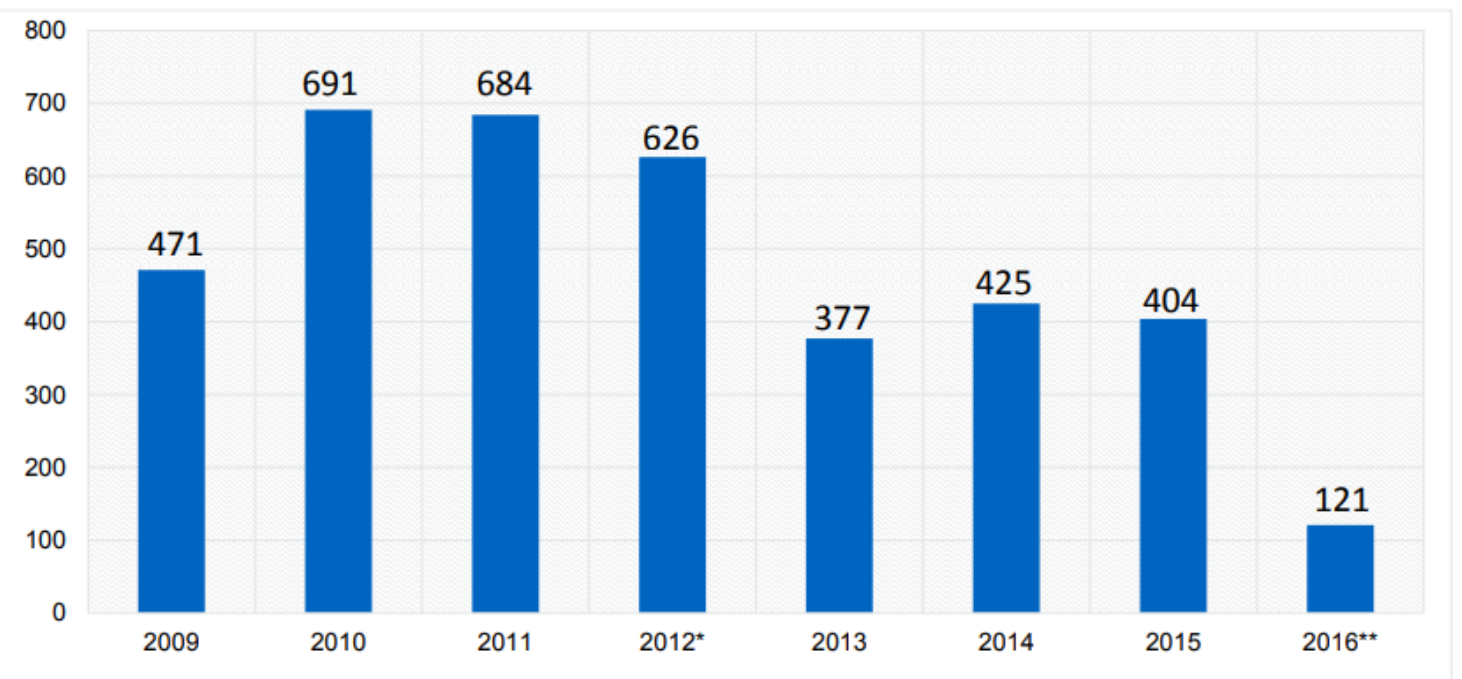

Fonte: Relatório CADE: Balanço 4 anos da nova Lei (2018, p. 5)

Qualquer que seja o motivo, o número de atos de concentração protocolizados perante o CADE se mantem decrescente no tempo apresentando; inclusive, fluxo harmônico de entrada e saída. Tal fato corrobora com a ideia de efetividade e eficácia, no SBDC, na análise dos atos de concentração que realmente podem afetar a economia nacional (vide Gráfico 3, abaixo). 


\section{Personalidade Acadêmica Homenageada:}

\section{Carlos Aurélio Mota de Souza (Universidade Ibirapuera - UNIB)}

Gráfico 3: Atos de concentração: entrada e saída

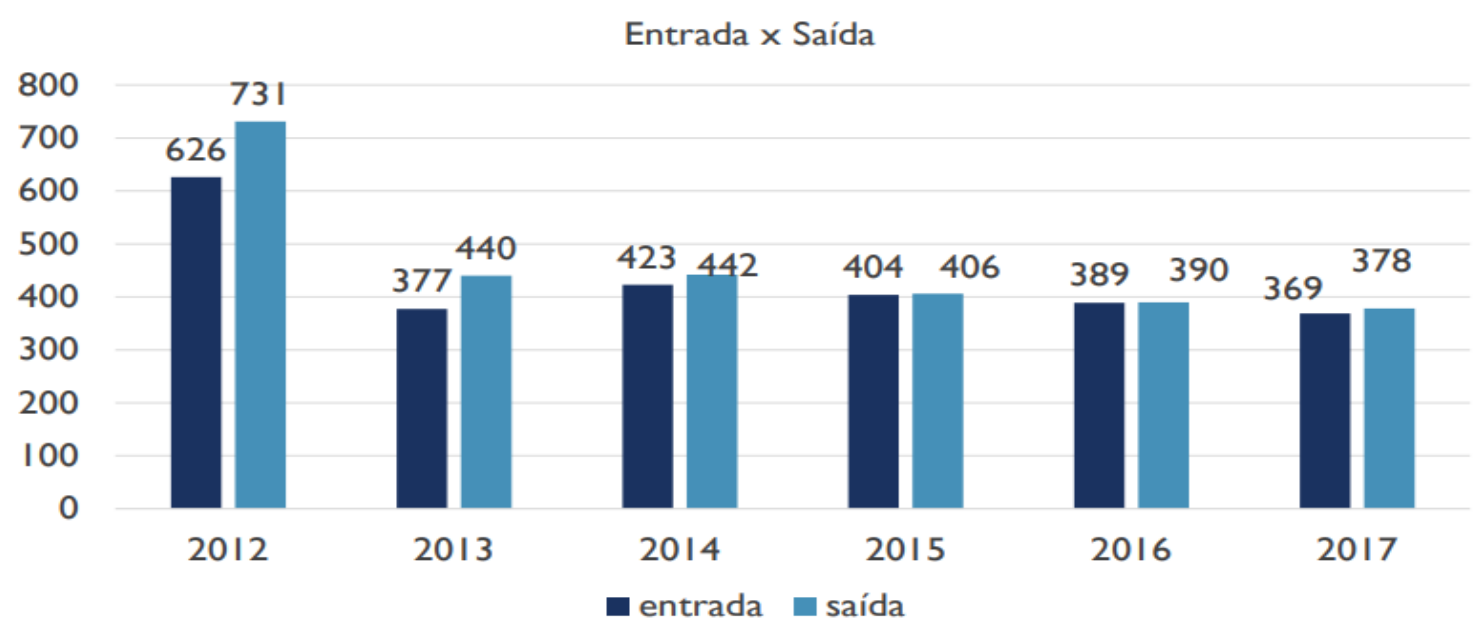

Fonte: Relatório CADE: Balanço - 2017 (2018, p. 4)

Em verdade, o SBDC vem se instrumentalizando, desde os anos 90, para lidar com uma economia que se abriu para o mercado internacional, mormente após o Governo Collor de Melo, em sintonia com um mundo globalizado e que passou a adotar os ditames do neoliberalismo, inclusive refletindo-se, no Direito, a necessária flexibilização normativa própria das necessidades de expansão do capital nacional e do internacional segundo, também, e inexorável, flexibilização das relações de produção.

A expansão capitalista do final do Séc. XX e início do Séc. XXI se coaduna, portanto com Sistemas Antitruste Nacionais que permitam estruturas de mercado competitivas no cenário internacional, ainda que, em determinados casos, indelevelmente, defendendo as estruturas monopolísticas reconhecidamente eficientes.

Outro ponto que merece destaque diz respeito ao tempo médio de tramitação dos processos relacionados à apreciação de atos de concentração. Se entre 2009 e 2011 o tempo médio de tramitação dos atos de concentração (considerando a instrução e o trâmite perante o CADE) era de 164 dias, entre 2013 e 2015², o tempo médio foi de 28 dias, conforme consta no Gráfico 4 a seguir.

\footnotetext{
${ }^{2}$ Anos de 2012 e 2016 desconsiderados, pois o primeiro teve atos noticiados sob a vigência de ambas
} as normas e o segundo apresenta informações incompletas no Gráfico 4. 


\section{Personalidade Acadêmica Homenageada:}

\section{Carlos Aurélio Mota de Souza (Universidade Ibirapuera - UNIB)}

Gráfico 4: Comparativo ano a ano: tempo de análise

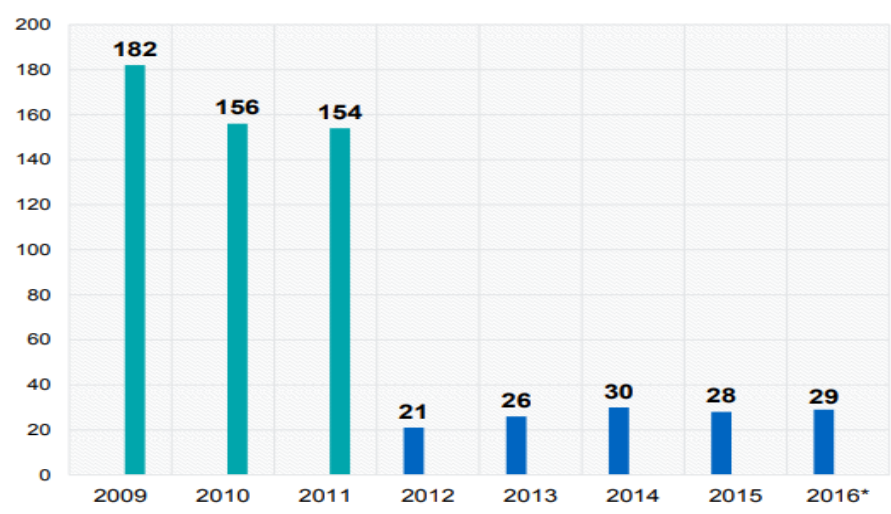

- Tempo médio geral de tramitação submetidos à Lei 12.529

- Tempo médio de tramitação submetidos à Lei 8.884 (instrução + Cade)

(*) Até 24 de maio

Fonte: Relatório CADE: Balanço 4 anos da nova lei $(2018$, p. 7$)$

A diminuição do tempo médio de tramitação põe "em xeque" o possível argumento contrário à submissão prévia de atos de concentração, segundo o qual a demora na apreciação dos atos de concentração pelo Cade poderia prejudicar os negócios firmados entre as empresas. Como se depreende do Gráfico 4, o Cade vem melhorando seu desempenho no que concerne ao tempo de análise das

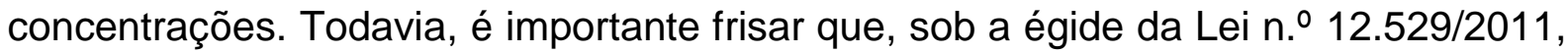
há diferença considerável no tempo de tramitação de atos de concentração em razão da escolha do rito (sumário ou ordinário), como demonstra o Gráfico 5. Em 2017, por exemplo, o tempo médio de tramitação dos atos de concentração foi de 30,1 dias. Entretanto, em se tratando de rito ordinário, a média subiu para 95,7 dias, contra 15,3 dias no rito sumário. 


\section{Personalidade Acadêmica Homenageada:}

\section{Carlos Aurélio Mota de Souza (Universidade Ibirapuera - UNIB)}

Gráfico 5: Atos de Concentração: tempo médio de tramitação

$$
(\mathrm{SG}+\text { Tribunal) }
$$

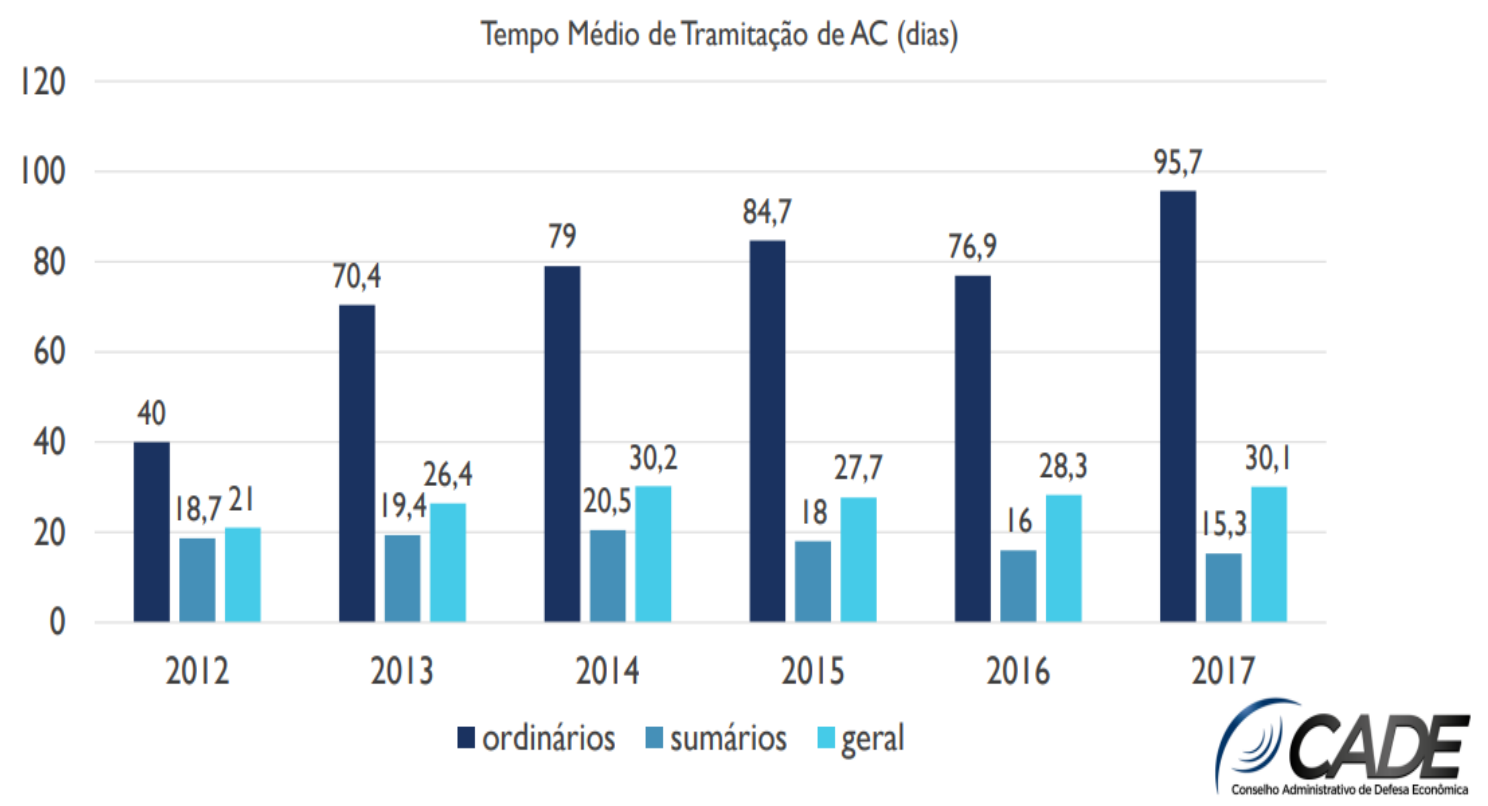

Fonte: Relatório CADE: Balanço-2017 (2018, p. 10)

Por fim, tem-se que a instituição do controle prévio dos atos de concentração trouxe ao cenário concorrencial um novo instituto, consistente no gun jumping, ou seja, a consumação prévia dos atos de concentração, mesmo sem a devida autorização do órgão Antitruste Nacional. A prática, vedada pela Lei n.․ 12.529/2011, entre os anos de 2012 e 2016, foi verificada em 8 de 1.738 atos de concentração analisados no SBDC, de acordo com o Cade (BALANÇO - 2016, 2018, p. 6).

Se por um lado os monopólios e oligopólios e, mesmo as concentrações econômicas per se não são condenáveis no Brasil, à luz da Lei 12.529/2011, a eficiência econômica é desiderato do SBDC, tanto que, na apresentação dos atos de concentração, devem ser provadas as respectivas eficiências e ganhos em mercado que a concentração empresarial propicia. Destarte, não se olvide que as ações em mercado e, inclusive, as concentrações econômicas devem estar coadunadas com o Princípio da Eficiência Econômico-Social (PEES) (GONÇALVES; STELZER, 2014), na medida em que se prime por uma economia socialmente-eficiente, já que tais concentrações se justificam uma vez apresentadas, ao SBDC, eficiências alocativas, 


\section{Personalidade Acadêmica Homenageada:}

Carlos Aurélio Mota de Souza (Universidade Ibirapuera - UNIB)

melhorias nos padrões de consumo, mantenimento do nível de empregabilidade, avanços tecnológicos, competitividade internacional, dentre outras importantes contribuições da concentração econômica para o Mercado Nacional que, afinal, é constitucionalmente protegido e integra o patrimônio nacional, conforme artigo 219 da Constituição da República Federativa do Brasil (CRFB/88, 2018).

Destarte, a concentração econômica está conforme ao PEES segundo se incluam, no cálculo para tomada de decisão, pelo SBDC, as necessárias variáveis de inclusão e responsabilidade social que se exige das empresas concentracionistas. Destarte, em função do PEES, deve-se perquirir por uma atuação empresarial adequada para a obtenção de máxima felicidade de todos os envolvidos no empreendimento (interna e externamente), segundo perspectiva social e economicamente inclusiva, (re) distribuição progressista dos escassos recursos e ação empresarial que vise o lucro (recompensa social de todos os envolvidos na prática empresarial ou que venham a ser, de alguma forma, presente ou futuramente atingidos ou beneficiados); lucro que, dizia-se, sendo privado, não pode desconsiderar o uso da riqueza social.

A tomada de decisão econômico-jurídica segundo o PEES deve levar em consideração: a um, a inclusão do maior número de variáveis no cálculo econométrico de custo e benefício; a dois, a consideração; para fins de cálculo e distribuição de benefícios ou imposição de custos - adjudicação de direitos, da totalidade dos agentes econômicos e das partes envolvidas, ou que venham a sofrer reflexos em virtude da tomada de decisão econômico-jurídica; a três, o primado da distribuição e redistribuição dos escassos recursos em função da eficiência econômico-social, segundo o Mínimo Ético Legal (MEL) determinado pelo Estado; a quatro, a eliminação dos reflexos das externalidades individuais ou coletivas que venham a determinar injustificáveis custos sociais, bem como, os reflexos da ação presente com relação às gerações futuras e; a cinco, a avaliação dos resultados da ação em sociedade a partir da consideração dos incentivos indutores ou obstantes da ação social.

Ao que se percebe, a novel legislação antitruste brasileira, no que tange ao controle dos atos de concentração, para além de melhorar os parâmetros de segurança jurídica através de critérios técnicos para a submissão dos atos de 


\section{Personalidade Acadêmica Homenageada:}

\section{Carlos Aurélio Mota de Souza (Universidade Ibirapuera - UNIB)}

concentração, por outro lado, acenou para os agentes econômicos nacionais que; agora, o SBDC não está se importando com todo e qualquer concentração, como já o fazia anteriormente (sob a égide da Lei $n .-0$ 8.884/94), mas com o controle dos atos que estão em patamar de importância (influência) bem maior para a economia nacional, disciplinando a ação dos grandes players que influenciam no mercado. Afinal, reduziram-se o número de análises dos atos concentracionais no SBDC em vista, especialmente, do nível de exigência para a apresentação do ato ao SBDC; qual seja, concentrações que importem a junção, fusão ou incorporação de players da economia cujo faturamento bruto no ano anterior ao de análise seja respectivamente de $\mathrm{R} \$ 750.000 .000,00$ e $\mathrm{R} \$ 75.000 .000,00$. Poder-se-ia tergiversar sobre as causas que levaram ao legislador tal opção; se falta de pessoal e meios para a atuação plena do Cade ou se por mera opção legislativa ou, ainda, em função de permitir maior competitividade internacional aos players nacionais; entretanto, o fato é que persiste o controle de estruturas no atual Sistema Brasileiro de Defesa da Concorrência.

\section{CONCLUSÃO}

Como se depreende dos dados apresentados, ao alterar os critérios de submissão, assim como o momento de notificação dos atos de concentração perante o Cade, a Lei n.. 12.529/2011 trouxe relevantes alterações ao cenário concorrencial brasileiro.

As referidas inovações ensejaram a diminuição do número de atos de concentração notificados perante a Autoridade Antitruste, a diminuição do tempo de trâmite dos processos voltados à aprovação ou reprovação de atos de concentração, além de introduzirem a figura do gun jumping ao Direito Concorrencial Pátrio.

A partir da análise dos dados mais recentes é possível defender que a modificação dos critérios para submissão obrigatória das concentrações perante o Cade, como esperado, tornou o procedimento mais claro, diminuindo o número de submissões desnecessárias. 
Personalidade Acadêmica Homenageada:

Carlos Aurélio Mota de Souza (Universidade Ibirapuera - UNIB)

Por outro lado, a partir dos dados sobre a duração dos procedimentos, seja sob o rito ordinário ou sumário, percebe-se a diminuição do tempo despendido pelo Cade na apreciação das concentrações. Esse cenário põe "em xeque" uma das possíveis críticas à instituição do controle prévio, já que a aprovação ou reprovação se dá em tempo satisfatório.

Em suma, tem-se que, com a entrada em vigor da Lei n.. $12.529 / 2011$, a atuação do Cade foi implementada, se tornando mais dinâmica e eficiente. Isso se deve às alterações já elencadas, as quais modificaram de forma substancial o controle estrutural da concorrência no Brasil.

De outra parte, ainda que em busca da necessária eficiência para a disciplina dos atos de concentração no Brasil, entende-se que o SBDC não pode afastar-se das premissas da ação inclusiva conforme ao Princípio da Eficiência Econômico Social (PEES).

\section{REFERÊNCIAS}

BAGNOLI, Vicente. Direito Econômico. 3. ed. São Paulo: Atlas, 2008.

BRASIL. Conselho Administrativo de Defesa Econômica. Balanço - 2017. Disponível em: <http://www.cade.gov.br/servicos/imprensa/balancos-eapresentacoes/apresentacao-balanco-

2017.pdf/@@download/file/Apresenta\%C3\%A7\%C3\%A3o-Balan\%C3\%A70\%20\%202017.pdf>. Acesso em: 22/10/2010.

. Conselho Administrativo de Defesa Econômica. Balanço - 2016. Disponível em: <http://www.cade.gov.br/servicos/imprensa/balancos-eapresentacoes/apresentacao-balanco2016.pdf/@@download/file/Apresenta\%C3\%A7\%C3\%A3o-Balan\%C3\%A70\%20\%202016.pdf>. Acesso em: 22/10/2010.

Conselho Administrativo de Defesa Econômica. Balanço 4 anos da nova lei. Disponível em: <http://www.cade.gov.br/servicos/imprensa/balancos-eapresentacoes/balanco-4-anos-nova-lei1.pdf/@@download/file/Balan\%C3\%A70\%204\%20anos\%20nova\%20lei.pdf>. Acesso em: 22/10/2010. 
Personalidade Acadêmica Homenageada:

Carlos Aurélio Mota de Souza (Universidade Ibirapuera - UNIB)

. Constituição da República Federativa do Brasil de 1988. Disponível em: http://www.planalto.gov.br/ccivil_03/constituicao/constituicao.htm. Acesso em: 22/10/2010.

Decreto n.o 9.266, de 15 de janeiro de 2018. Altera o Decreto o 9.003, de 13 de março de 2017, que aprova a Estrutura Regimental e o Quadro Demonstrativo dos Cargos em Comissão e das Funções de Confiança do Ministério da Fazenda, remaneja cargos em comissão e funções de confiança, substitui cargos em comissão do Grupo-Direção e Assessoramento Superiores - DAS por Funções Comissionadas do Poder Executivo - FCPE, e altera o Decreto oㅜ 9.075, de 6 de junho de 2017, que dispõe sobre a composição e as competências da Comissão de Financiamentos Externos. Disponível em: http://www.planalto.gov.br/ccivil_03/_ato20152018/2018/decreto/D9266.htm. Acesso em: 22/10/2010.

Lei $\mathrm{n} . \mathbf{0}$ 12.529, de 30 de novembro de 2011. Estrutura o sistema brasileiro de defesa da concorrência e dá outras providências. Disponível em: <http://www.planalto.gov.br/ccivil_03/_ato2011-2014/2011/Lei/L12529.htm>. Acesso em: 22/10/2010.

. Lei n.o 8.884, de 11 de junho de 1994. Transforma o Conselho Administrativo de Defesa Econômica (CADE) e Autarquia, dispõe sobre a prevenção e a repressão às infrações a ordem econômica e dá outras providências. Disponível em: <http://www.planalto.gov.br/ccivil_03/leis//8884.htm>. Acesso em: 22/10/2010.

- Ministério da Fazenda. Secretaria de Acompanhamento Econômico Seae. Disponível em: http://www.fazenda.gov.br/orgaos/seae. Acesso em: 22/10/2010.

Portaria Interministerial $\mathrm{n} . \mathbf{9}$ 994, de 30 de maio de 2012. Adequa, após indicação do Plenário do Conselho Administrativo de Defesa Econômica - CADE, os valores constantes do art. 88, I e II, da Lei 12.529, de 30 de novembro de 2011. Disponível em: <http://www.cade.gov.br/assuntos/normas-elegislacao/portarias/portaria-994.pdf/@@download/file/Portaria\%20994.pdf>. Acesso em: 22/10/2010.

CASTRO, Ramsés Maciel de. A responsabilização do conselho administrativo de defesa econômica na análise dos atos de concentração. Revista Magister de Direito Empresarial, Concorrencial e do Consumidor. Porto Alegre, 2012, vol. 44, abr.maio.

. Controle dos atos de concentração de empresas realizados no Brasil e em países economicamente mais desenvolvidos: justificativas para um regime normativo diferenciado no brasil. Revista Magister de Direito Empresarial, Concorrencial e do Consumidor. Porto Alegre, 2013, vol. 50, abr.-maio. 
Personalidade Acadêmica Homenageada:

Carlos Aurélio Mota de Souza (Universidade Ibirapuera - UNIB)

COELHO, Fábio Ulhoa. Curso de Direito Comercial: direito de empresa. vol. 3. 12. ed. São Paulo: Saraiva, 2011.

CORDOVIL, Leonor et al. A nova lei de defesa da concorrência comentada: lei 12.529, de 30 de novembro de 2011. São Paulo: Editora Revista dos Tribunais, 2011.

FAGUNDES, Jorge. Análise antitruste e atos de concentração no setor bancário. In: MARANHÃO, Juliano Souza de Albuquerque; CÉSAR, Joaquim Portes de Cerqueira (Org.). Direito antitruste no setor financeiro. São Paulo: Editora Singular, 2012.

FÁZZIO JUNIOR, Waldo. Manual de Direito Comercial. 15. ed. São Paulo: Atlas, 2014.

FORGIONI, Paula A. Os fundamentos do Antitruste. 8. ed. rev. e atual. São Paulo: Editora Revista dos Tribunais, 2015.

GABAN, Eduardo Molan; DOMINGUES, Juliana Oliveira. Direito Antitruste. 3. ed. São Paulo: Saraiva, 2012.

GONÇALVES, Everton das Neves e STELZER, Joana. Aspectos econômico-jurídicos da nova Lei de Defesa da Concorrência Brasileira. In PINTO, Felipe Chiarello de Souza; SOARES, Sônia Barroso Brandão; CLARK, Giovani (Orgs.). Direito e Economia. XXI CONPEDI Niterói, RJ. Florianópolis, SC: Fundação José Boiteux; 2012. Pp. 263-283. ISBN 978-85-7840-117-7. Disponível em $<$ http://www.publicadireito.com.br/artigos/?cod=9f8684e630c4c30c $>$. Acesso em 22/10/2010.

Brazilians Law: the normative and judicial decision taking. In Sequencia: Estudos Jurídicos e Políticos, (S. I.), v. 35, n. 68, pp. 261-290, Jun. 2014. ISSN 2177-7055. Disponível em: <https://periodicos.ufsc.br/index.php/sequencia/article/view/21777055.2013v35n68p261/26955>. Acesso em: 22/10/2010. Doi: <http://dx.doi.org/10.5007/2177-7055.2013v35n68p261>.

RODRIGUES, Eduardo Frade; ARAÚJO, Gilvandro Vasconcelos Coelho de. Os 5 primeiros anos de aplicação da lei n. 12.529/11: a defesa da concorrência avança no Brasil. In: $\mathbf{5}$ anos lei de defesa da concorrência: gênese, jurisprudência e desafios para o futuro. Coordenação: Eduardo Caminati Anders et al. IBRAC, 2017.

SCHNEIDER, Andressa C. Aspectos do controle de atos de concentração e da tutela do consumidor: cotejo entre as leis 8.884/1994 e 12.529/2011. Boletim latinoamericano de concorrência, ‥ $\mathrm{31}$, abr., 2012. 